\title{
Validation of Conventional Thromboembolic Risk Factors in a Korean Atrial Fibrillation Population - Suggestion for a Novel Scoring System, $\mathrm{CHA}_{2} \mathrm{DS}_{2}-\mathrm{VAK}$ -
}

\author{
Myung-Jin Cha, MD; Youngjin Cho, MD; Il-Young Oh, MD, PhD; \\ Eue-Keun Choi, MD, PhD; Seil Oh, MD, PhD
}

\begin{abstract}
Background: There is little evidence that focuses on the ethnic variability of clinical risk factors for thromboembolism (TE) in atrial fibrillation (AF). We aimed to investigate the effect of each traditional risk factor in the Korean AF population.

Methods and Results: Medical records of 12,876 consecutive patients (aged >18 years) newly diagnosed and followed up with non-valvular AF from 2000 to 2013 were reviewed. TE events, including ischemic stroke and systemic embolism, were investigated for risk factor validation. Among the total of 12,876 patients, $1,390(10.8 \%)$ had TE events. In univariate/multivariate analysis adjusting for clinical factors and antithrombotic medications, traditional risk factors included in the $\mathrm{CHA}_{2} \mathrm{DS}_{2}$-VASc scheme showed statistical significance, except for female sex, which was not a predictor of events. Additionally, chronic kidney disease (CKD; hazard ratio 1.62, $\mathrm{P}<0.001$ ) was shown to be an independent predictor of TE events. Based on the analysis, we developed a novel stratification system, $\mathrm{CHA}_{2} \mathrm{DS}_{2}-\mathrm{VAK}$, omitting the female sex category and adding CKD. The new scoring system showed greater discrimination in event rates between score 0 and 1 patients.
\end{abstract}

Conclusions: Female sex was not associated with TE events in a Korean non-valvular AF population. The novel $\mathrm{CHA}_{2} \mathrm{DS} \mathrm{S}_{2}-\mathrm{VAK}$ scoring system, with substitution of CKD for female sex, might be more appropriate for the Korean population.

Key Words: Atrial fibrillation; $\mathrm{CHA}_{2} \mathrm{DS}_{2}-\mathrm{VAK}$; Chronic kidney disease; Females; Thromboembolism

C urrent risk stratification schemes for atrial fibrillation (AF) have shown modest predictive power for thromboembolic (TE) events (C-statistics approximately 0.6).1,2 However, many potential factors have not been fully assessed, because of a lack of systemic reviews in large populations. Chronic kidney disease (CKD) is one such potential factor considered as a predictor for TE events in AF patients. ${ }^{3,4}$ Recent findings suggest that a creatinine clearance of $\leq 60 \mathrm{~mL} / \mathrm{min}$ or less may even be an independent predictor of stroke and systemic embolism. ${ }^{5}$

There is little evidence supporting ethnic variability of TE risk evaluation for AF. Traditional risk stratification systems have been developed based on Western population cohorts, ${ }^{6}$ the most popular being the $\mathrm{CHA}_{2} \mathrm{DS}_{2}-\mathrm{VASc}$ system, which was also based on the Birmingham scheme and refined using European cohorts. ${ }^{7}$ Recently, Japanese investigators reported that female sex is not a risk factor for TE events among Japanese non-valvular AF patients mostly treated with warfarin. ${ }^{8}$ In the current AF guidelines, $\mathrm{CHA}_{2} \mathrm{DS}_{2}$-VASc score of 1 with female factor is not considered as an anticoagulation indication.

The objective of this study was to create a novel scheme for use in Asian AF patients by refining and incorporating traditional and potential risk factors. The new scoring system was then compared with existing systems.

\section{Methods}

Our study protocol was approved by the institutional review boards in Seoul National University Hospital and was in accordance with the Declaration of Helsinki.

\section{Study Population}

The study population was from a real-world, retrospective single-center cohort. Consecutive patients aged $>18$ years, who were newly diagnosed with non-valvular AF and followed up from 2000 to 2013 were systemically analyzed. Patients whose renal function was not assessed at the time of AF diagnosis or who did not visit the clinic more than twice were excluded from the analysis. Patients with follow-up duration $<30$ days were also excluded from the analysis. The study patients visited the cardiovascular center every 3 or 4 months. Follow-up data were obtained from medical record review. Because the patients included

Received February 19, 2018; revised manuscript received August 15, 2018; accepted August 21, 2018; released online October 4, 2018 Time for primary review: 51 days

Department of Internal Medicine, Seoul National University Hospital, Seoul (M.-J.C., E.-K.C., S.O.); Department of Internal Medicine, Seoul National University Bundang Hospital, Gyeonggi (Y.C., I.-Y.O.), Korea

Mailing address: Seil Oh, MD, PhD, FHRS, FESC, Professor of Internal Medicine, Seoul National University College of Medicine, Seoul National University Hospital, 101 Daehak-ro, Jongno-gu, Seoul 110-744, Korea. E-mail: seil@snu.ac.kr

ISSN-1346-9843 All rights are reserved to the Japanese Circulation Society. For permissions, please e-mail: cj@j-circ.or.jp 
in this cohort (including patients from 2000 to 2013) were treated prior to the release of non-vitamin $\mathrm{K}$ antagonist oral anticoagulant in Korea, all patients with anticoagulants were prescribed warfarin.

\section{Definition and Validation of TE Risk Factors}

Risk factors were defined according to previous AF guidelines. ${ }^{7,9}$ Hypertension was defined as resting blood pressure $\geq 140 \mathrm{mmHg}$ systolic and/or $\geq 90 \mathrm{mmHg}$ diastolic on at least 2 occasions, or being on antihypertensive pharmacologic therapy. Diabetes was defined as fasting glucose $\geq 126 \mathrm{mg} / \mathrm{dL}$, hemoglobin Alc $\geq 6.5 \%$, or use of diabetes medications. Vascular disease included myocardial infarction, peripheral artery disease and presence of complex aortic plaque. Heart failure (HF) was defined as signs/symptoms of HF or objective evidence of reduced left ventricular ejection fraction $(<40 \%)$. CKD was defined as presence of kidney damage or pathologically reduced glomerular filtration rate (MDRD estimated GFR $<60 \mathrm{~mL} / \mathrm{min} / 1.73 \mathrm{~m}^{2}$ ) for more than 3 months, irrespective of the cause, according to KDIGO guidelines. ${ }^{10}$ When a diagnosis of any risk factor was unclear, we referred to the medical records of the responsible physician. TE events were defined as ischemic stroke, transient ischemic attack (TIA) and systemic embolism. Ischemic stroke included all types of stroke with an ischemic cause, and hemorrhagic stroke was classified as bleeding. ${ }^{9}$
CHA2DS2-VAK: a Novel Stratification System

$\mathrm{CHA}_{2} \mathrm{DS}_{2}-\mathrm{VASc}$ was renamed $\mathrm{CHA}_{2} \mathrm{DS}_{2}$-VAK because the "S" ex "c"ategory was replaced with "K"idney disease (Table 1). This new system was based on the validation results described here.

\section{Statistical Analysis}

Continuous variables are presented as mean \pm standard deviation. The risk of ischemic stroke was analyzed by univariate and multivariate Cox proportional-hazards method. A 95\% confidence interval (CI) is reported with predictive values. The means were compared using Student's t-test. Categorical variables were compared by Fisher's

\begin{tabular}{|lc|}
\hline \multicolumn{1}{|c|}{$\begin{array}{c}\text { Table 1. Nisk factor } \\
\text { Novel Thromboembolic Risk Stratification System } \\
\text { (CHA2DS2-VAK) }\end{array}$} \\
Congestive heart failure & Score \\
Hypertension & 1 \\
Age $\geq 75$ years & 1 \\
Diabetes mellitus & 2 \\
Stroke/TIA/thromboembolism & 1 \\
Vascular disease & 2 \\
Age $65-74$ years & 1 \\
Chronic Kidney disease & 1 \\
Total & 1 \\
\hline
\end{tabular}

TIA, transient ischemic attack.

\begin{tabular}{|c|c|c|c|c|}
\hline & \multirow{2}{*}{$\begin{array}{c}\text { Total } \\
(n=12,876)\end{array}$} & \multicolumn{2}{|c|}{ Thromboembolic event } & \multirow{2}{*}{$P$ value } \\
\hline & & Yes $(n=1,390)$ & No $(n=11,486)$ & \\
\hline Age (years) & $64.9 \pm 12.0$ & $68.4 \pm 9.6$ & $64.5 \pm 12.2$ & $<0.001$ \\
\hline $65-74$ & $4,746(36.9 \%)$ & $573(41.2 \%)$ & $4,173(36.3 \%)$ & $<0.001$ \\
\hline$\geq 75$ & $2,594(20.1 \%)$ & 377 (27.1\%) & 2,217 (19.3\%) & $<0.001$ \\
\hline Female & $4,700(36.5 \%)$ & $540(38.8 \%)$ & $4,160(36.2 \%)$ & 0.055 \\
\hline Hypertension & $4,203(32.6 \%)$ & 726 (52.2\%) & $3,477(30.3 \%)$ & $<0.001$ \\
\hline Diabetes & $2,539(19.7 \%)$ & $404(29.0 \%)$ & $2,135(18.6 \%)$ & $<0.001$ \\
\hline Previous TE event & $481(3.7 \%)$ & $87(6.3 \%)$ & $394(3.4 \%)$ & $<0.001$ \\
\hline Vascular disease & $661(5.1 \%)$ & $121(8.7 \%)$ & $540(4.7 \%)$ & $<0.001$ \\
\hline CKD & $3,712(28.8 \%)$ & $536(38.6 \%)$ & $3,176(27.7 \%)$ & $<0.001$ \\
\hline Heart failure & $2,228(17.3 \%)$ & 318 (22.9\%) & $1,910(16.6 \%)$ & $<0.001$ \\
\hline $\mathrm{CHA}_{2} \mathrm{DS}_{2}-\mathrm{VASc}$ score & $1.72 \pm 1.22$ & $2.26 \pm 1.24$ & $1.65 \pm 1.20$ & $<0.001$ \\
\hline 0 & $1,866(14.5 \%)$ & $67(4.9 \%)$ & $1,799(15.7 \%)$ & \\
\hline 1 & 4,357 (33.8\%) & $335(24.1 \%)$ & $4,022(35.0 \%)$ & \\
\hline 2 & $3,660(28.4 \%)$ & $445(32.0 \%)$ & $3,215(28.0 \%)$ & \\
\hline 3 & $1,935(15.0 \%)$ & $331(23.8 \%)$ & $1,604(14.0 \%)$ & \\
\hline$\geq 4$ & $1,058(8.2 \%)$ & $212(15.3 \%)$ & $846(7.4 \%)$ & \\
\hline Hemoglobin (g/dL) & $12.9 \pm 1.9$ & $12.7 \pm 1.9$ & $13.0 \pm 2.0$ & $<0.001$ \\
\hline Creatinine & $1.24 \pm 1.06$ & $1.30 \pm 0.99$ & $1.24 \pm 1.07$ & 0.036 \\
\hline $\operatorname{GFR}\left(\mathrm{mL} / \mathrm{min} / 1.73 \mathrm{~m}^{2}\right)$ & $68.4 \pm 22.9$ & $64.1 \pm 22.1$ & $68.9 \pm 22.9$ & $<0.001$ \\
\hline Cholesterol & $163.7 \pm 32.9$ & $158.4 \pm 29.4$ & $164.4 \pm 33.3$ & $<0.001$ \\
\hline LDL (mg/dL) & $99.2 \pm 27.9$ & $95.6 \pm 24.3$ & $99.8 \pm 28.4$ & $<0.001$ \\
\hline $\mathrm{HbA1c}(\%)$ & $6.4 \pm 1.0$ & $6.3 \pm 0.9$ & $6.4 \pm 1.1$ & 0.017 \\
\hline Antiplatelets & $4,705(36.5 \%)$ & $507(36.4 \%)$ & $4,198(36.6 \%)$ & 0.929 \\
\hline Anticoagulation & $4,386(34.1 \%)$ & $80(5.7 \%)$ & $4,306(37.5 \%)$ & $<0.001$ \\
\hline No anticoagulant & $3,703(28.8 \%)$ & $782(56.2 \%)$ & $2,921(25.4 \%)$ & $<0.001$ \\
\hline Follow-up duration (years) & $4.67 \pm 3.72$ & $4.86 \pm 3.68$ & $4.46 \pm 3.63$ & $<0.001$ \\
\hline
\end{tabular}

CKD, chronic kidney disease; GFR, glomerular filtration rate; LDL, low-density lipoprotein; TE, thromboembolism. 


\begin{tabular}{|c|c|c|c|c|c|c|}
\hline & \multicolumn{3}{|c|}{ Univariate analysis } & \multicolumn{3}{|c|}{ Multivariate analysis } \\
\hline & HR & $95 \% \mathrm{Cl}$ & $P$ value & HR & $95 \% \mathrm{Cl}$ & $P$ value \\
\hline Age & 1.05 & $1.04-1.05$ & $<0.001$ & 1.04 & $1.03-1.04$ & $<0.001$ \\
\hline Age $\geq 75$ years & 2.14 & $1.89-2.41$ & $<0.001$ & & & \\
\hline Female & 1.06 & $0.95-1.17$ & 0.325 & 0.96 & $0.86-1.07$ & 0.411 \\
\hline Hypertension & 1.95 & $1.76-2.17$ & $<0.001$ & 1.59 & $1.44-1.80$ & $<0.001$ \\
\hline Diabetes & 1.49 & $1.33-1.68$ & $<0.001$ & 1.23 & $1.10-1.40$ & $<0.001$ \\
\hline Previous TE event & 2.20 & $1.77-2.73$ & $<0.001$ & 1.57 & $1.26-1.96$ & $<0.001$ \\
\hline Vascular disease & 1.76 & $1.46-2.12$ & $<0.001$ & 1.23 & $1.02-1.49$ & 0.043 \\
\hline CKD & 1.62 & $1.45-1.80$ & $<0.001$ & 1.17 & $1.04-1.31$ & 0.007 \\
\hline Heart failure & 1.25 & $1.11-1.42$ & $<0.001$ & 1.19 & $1.05-1.36$ & 0.007 \\
\hline Anticoagulation & 0.10 & $0.08-0.13$ & $<0.001$ & 0.11 & $0.09-0.14$ & $<0.001$ \\
\hline
\end{tabular}

$\mathrm{Cl}$, confidence interval; CKD, chronic kidney disease; HR, hazard ratio; TE, thromboembolism.

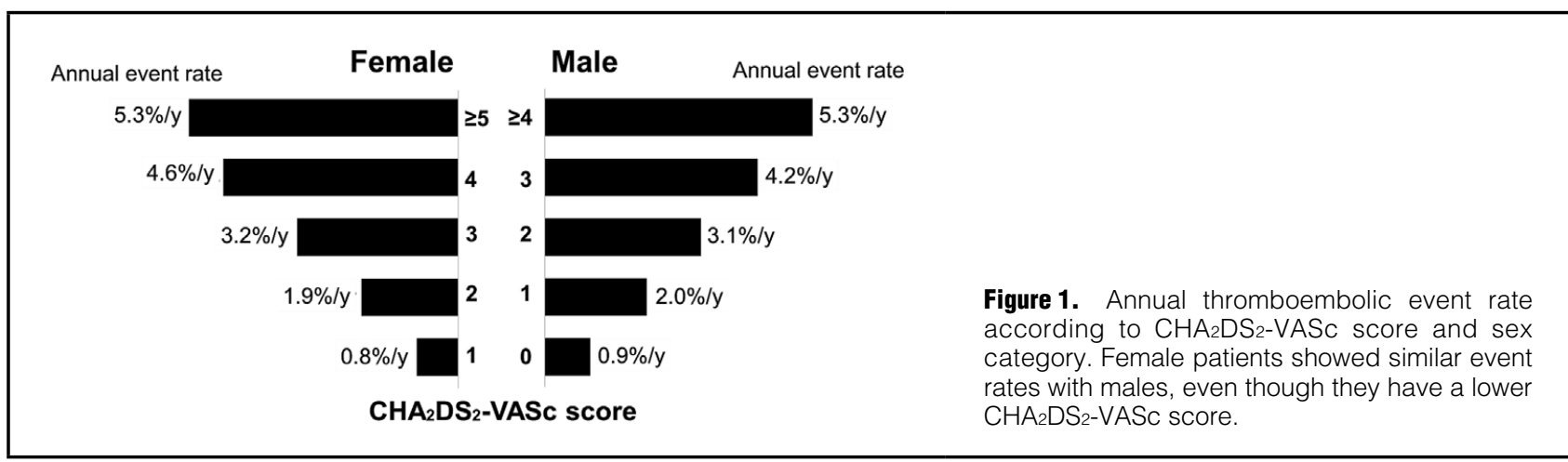

exact test and the $\chi^{2}$ test.

We validated each risk factor (age, sex, HF, hypertension, diabetes, previous stroke history, vascular disease and CKD) by univariate and multivariate Cox survival model. In multivariate survival analysis, TE prophylaxis (none/ antiplatelet agent/ anticoagulant) was compensated as a covariate. The novel stratification system was derived from the above statistical analyses. Model comparison between the novel system and the $\mathrm{CHA}_{2} \mathrm{DS}_{2}-\mathrm{VASc}$ scheme was achieved using the area under curve (AUC) of receiveroperator curves (ROC). Subgroup analyses for the patients with $\mathrm{CHA}_{2} \mathrm{DS}_{2}$-VASc score of 1 and oral anticoagulantnaïve patients were done.

$\mathrm{P}<0.05$ was considered statistically significant. Statistical analyses were performed using SPSS Statistics 21.0 software package (IBM SPSS, New York, USA).

\section{Results}

In total, 12,876 consecutive non-valvular AF patients were enrolled. There were 1,390 (10.8\%) TE events during the study period. Baseline characteristics are described in Table 2. The prevalence of traditional risk factors was significantly different between patients with and without TE events, except for female sex.

\section{TE Risk Factor Verification}

In the univariate analysis, female sex did not show predictive power for TE events. Age over 75 years and a history of previous TE events, which are granted 2 points each in the $\mathrm{CHA}_{2} \mathrm{DS}_{2}-\mathrm{VASc}$ system, showed a higher hazard ratio than other significant risk factors such as hypertension, diabetes, vascular disease and CKD. For age factor validation, we re-analyzed the stroke risk by dividing the age into 5 -year groups and the results are described in Figure S1. In this analysis, the TE risk began to increase from age 60 , and increased sharply at age 65 , and overuse of anticoagulation was also a significant determinant for prediction. In the multivariate analysis, most risk factors retained their predictive power, although female sex was still not a significant predictor for TE events (Table 3). In the subgroup of patients not on anticoagulants $(n=8,490$, Table S1), females sex was not a predictor for TE events $(\mathrm{P}=0.539)$, but $\mathrm{CKD}$ was a significant predictor for outcome $(\mathrm{P}<0.001)$ (Table S2).

Female sex did not show significant predictive power for TE events among the study population $(\mathrm{P}=0.325$, Table 2$)$. The risk of patients with $\mathrm{CHA}_{2} \mathrm{DS}_{2}-\mathrm{VASc}=0$ was not statistically different from those with score 1 for female sex. The risk of male patients with score 1 was not different from female patients with score 2 (Figure 1). There was a significant difference in the TE risk between sex category in the same $\mathrm{CHA}_{2} \mathrm{DS}_{2}-\mathrm{VASc}$ score $(\mathrm{P}<0.001$ in score 1 , $\mathrm{P}=0.001$ in score 2 , and $\mathrm{P}=0.044$ in score $\geq 3$ patients). The Kaplan-Meier curves for TE events according to sex and $\mathrm{CHA}_{2} \mathrm{DS}_{2}$-VASc score in anticoagulant-naïve patients are shown in Figure S2. The subgroup analysis of the female factor showed no prognostic power for TE events (Figure S3).

CKD was an important predictor for TE events (HR $1.62, \mathrm{P}<0.001$ in univariate analysis). The multivariate analysis correcting for conventional risk factors included in the $\mathrm{CHA}_{2} \mathrm{DS}_{2}-\mathrm{VASc}$ scoring system also showed that 
CKD significantly predicted TE risk (Table 3 ). TE risk was shown to increase as GFR decreased (Figure 2).

\section{$\mathrm{CHA}_{2}$ DS2-VAK: a Novel Stratification System}

In the traditional $\mathrm{CHA}_{2} \mathrm{DS}_{2}-\mathrm{VASc}$ scoring system, risk of TE events increased according to score. Compared with patients with score 0 , risk for patients with score 1 showed a 2.10 -fold increase $(95 \%$ CI $1.64-2.77, \mathrm{P}<0.001)$, score 2 patients had a 3.42 -fold increase $(95 \%$ CI $2.64-4.42$, $\mathrm{P}<0.001)$, score 3 patients had a 4.69 -fold increase $(95 \% \mathrm{CI}$ 3.61-6.12. $\mathrm{P}<0.001$ ), and score $>3$ patients had a 5.86 -fold increase (95\% CI 4.46-7.72, $\mathrm{P}<0.001)$. The AUC of the CHA2DS2-VASc in the cohort was $0.639(95 \%$ CI 0.62 $0.65, \mathrm{P}<0.001)$ by ROC curve.

To enhance the predictive and discriminative power of the $\mathrm{CHA}_{2} \mathrm{DS}_{2}-\mathrm{VASc}$ scheme, we to substituted the female category with $\mathrm{CKD}$ and renamed. $\mathrm{CHA}_{2} \mathrm{DS}_{2}-\mathrm{VASc}$ as $\mathrm{CHA}_{2} \mathrm{DS}_{2}-\mathrm{VAK}$ (Table 1). Based on the relative risk in this study, age over 75 years and previous stroke history were given 2 points each as in the $\mathrm{CHA}_{2} \mathrm{DS}_{2}$-VASc scoring system. The new $\mathrm{CHA}_{2} \mathrm{DS}_{2}-\mathrm{VAK}$ system had an AUC of $0.650(95 \%$ CI $0.64-0.66, \mathrm{P}<0.001)$. Compared to patients with $\mathrm{CHA}_{2} \mathrm{DS}_{2}$-VAK score 0 , patients with score 1 had a 2.43 -fold increase in risk $(95 \%$ CI $1.94-3.05, \mathrm{P}<0.001)$, score 2 patients had a 3.40 -fold increase $(95 \%$ CI $2.72-$ $4.25, \mathrm{P}<0.001$ ), score 3 patients had a 5.43-fold increase (95\% CI 4.33-6.81, $\mathrm{P}<0.001)$, and patients with score over 3 had a 5.91-fold increase in risk ( $95 \%$ CI 4.66-7.51, $\mathrm{P}<0.001)$.

The annual TE event rate for both the $\mathrm{CHA}_{2} \mathrm{DS}_{2}$-VAK and $\mathrm{CHA}_{2} \mathrm{DS}_{2}-\mathrm{VASc}$ scheme are described in Table 4. The data for anticoagulant-naïve patients are shown in Table S3. Applying the new system, a total of 5,296 (41.1\%) patients have changes in their risk stratification. There were 2,154 $(16.7 \%)$ patients getting an additional point, and 3,142 $(24.2 \%)$ patients lost 1 point from their $\mathrm{CHA}_{2} \mathrm{DS}_{2}$-VASc scores. Detailed data of patients with changes when converting to the $\mathrm{CHA}_{2} \mathrm{DS}_{2}-\mathrm{VAK}$ score are described in Table S4. The difference according to the $\mathrm{CHA}_{2} \mathrm{DS}_{2}-\mathrm{VAK}$ scores $(0,1$, and 2$)$ derived from a $\mathrm{CHA}_{2} \mathrm{DS}_{2}$-VASc score of 1 was further analyzed. The new system better discriminated intermediate-risk patients (Figure 3). In this analysis, $\mathrm{CHA}_{2} \mathrm{DS}_{2}$-VAK score 2 patients had a 3 -fold increased risk of TE than score 0 patients (HR 3.35, 95\% CI 2.294.92, $\mathrm{P}<0.001)$, even though their $\mathrm{CHA}_{2} \mathrm{DS}_{2}-\mathrm{VASc}$ scores were the same at 1 .

\section{Discussion}

The main findings of the present study were as follows. (1) In this Korean AF cohort, female sex was not associated with increased risk of TE events. (2) CKD predicted TE

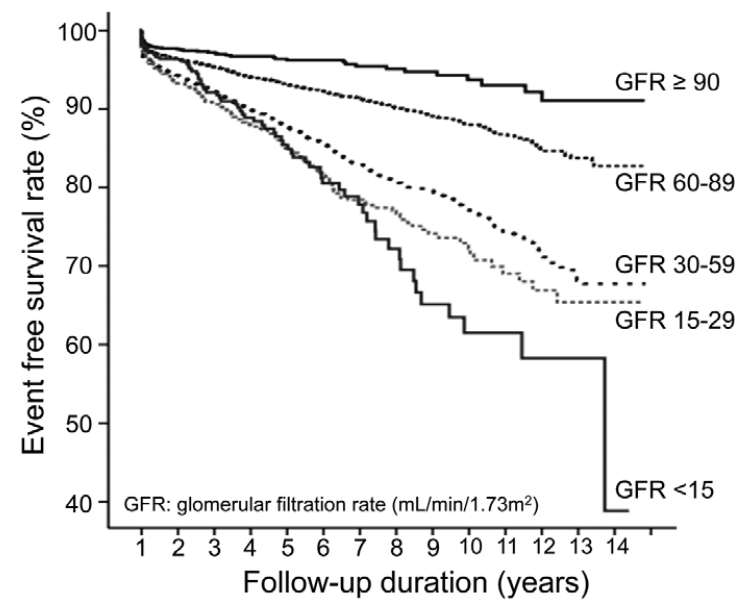

Figure 2. Thromboembolic event-free survival rate according to glomerular filtration rate (GFR). Thromboembolic risk increased as GFR decreased. Patients with GFR $<60 \mathrm{~mL} /$ $\mathrm{min} / 1.73 \mathrm{~m}^{2}$ showed significantly higher event rates than patients with GFR $>60 \mathrm{~mL} / \mathrm{min} / 1.73 \mathrm{~m}^{2}$.

events similarly to $\mathrm{CHA}_{2} \mathrm{DS}_{2}$-VASc components, except for female sex. Based on these findings, we created a novel stratification system, $\mathrm{CHA}_{2} \mathrm{DS}_{2}-\mathrm{VAK}$, which is an acronym for modified HF, hypertension, age, diabetes, stroke history, vascular disease, age 65-74 and kidney disease. This new system enhanced discrimination of low to intermediate TE risk in AF patients.

The trend of increasing age at AF diagnosis in the Korean population aligns with data gathered in Western studies. ${ }^{11,12}$ As the age at diagnosis increases, more patients have $\geq 1$ points starting at diagnosis, and distinguishing AF patients with intermediate risk has become an important issue. Many potential TE risk factors for AF have been suggested, including clinical factors, biomarkers, and brain imaging. ${ }^{13,14}$ Although this facilitates a systematic approach to AF evaluation, there are concerns that newly incorporated factors will create score inflation as well. With the novel $\mathrm{CHA}_{2} \mathrm{DS}_{2}$-VAK system, the number of low- to intermediate-risk patients (scores 0 and 1) are increased, but the ability to predict risk is more powerful. The change in category has importance in these groups, because it could lead to changes in antithrombotic strategy.

In Western cohorts, women with AF have a moderately increased risk of stroke compared with men, ${ }^{15,16}$ but this finding has not had consistency in Asian studies. Recently,

\begin{tabular}{|c|c|c|c|c|c|c|c|c|}
\hline & \multicolumn{4}{|c|}{$\mathrm{CHA}_{2} \mathrm{DS}_{2}$-VAK } & \multicolumn{4}{|c|}{$\mathrm{CHA}_{2} \mathrm{DS}_{2}$-VASc } \\
\hline & Total & Events & $\begin{array}{c}\text { Annual } \\
\text { incidence rate }\end{array}$ & HR (95\% Cl) & Total & Events & $\begin{array}{c}\text { Annual } \\
\text { incidence rate }\end{array}$ & HR (95\% Cl) \\
\hline 0 & 2,617 & 105 & $0.84 \%$ & 1.00 (Ref.) & 1,866 & 67 & $0.84 \%$ & 1.00 (Ref.) \\
\hline 1 & 3,392 & 271 & $1.81 \%$ & $2.43(1.94-3.05)$ & 4,357 & 335 & $1.78 \%$ & $2.13(1.64-2.78)$ \\
\hline 2 & 3,044 & 333 & $2.62 \%$ & $3.40(2.72-4.25)$ & 3,660 & 445 & $2.84 \%$ & $3.41(2.64-4.42)$ \\
\hline 3 & 2,112 & 346 & $4.00 \%$ & $5.43(4.33-6.81)$ & 1,935 & 331 & $3.88 \%$ & $4.70(3.61-6.11)$ \\
\hline$\geq 4$ & 1,711 & 335 & $4.15 \%$ & $5.91(4.66-7.51)$ & 1,058 & 212 & $4.94 \%$ & $5.86(4.46-7.72)$ \\
\hline
\end{tabular}

$\mathrm{Cl}$, confidence interval; $\mathrm{HR}$, hazard ratio. 


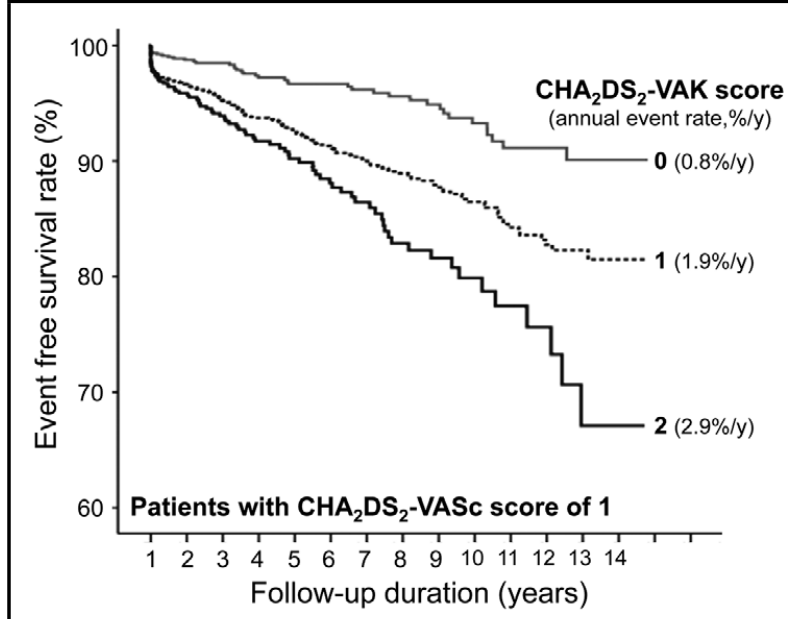

Figure 3. Difference in thromboembolic event rates according to $\mathrm{CHA}_{2} \mathrm{DS}_{2}-\mathrm{VAK}$ score among patients with the same $\mathrm{CHA}_{2} \mathrm{DS}_{2}-\mathrm{VASc}$ score of 1 . Patients with $\mathrm{CHA}_{2} \mathrm{DS} 2-\mathrm{VASc}$ of 1 were differentiated into a $\mathrm{CHA}_{2} \mathrm{DS}_{2}-\mathrm{VAK}$ score of $\mathrm{O}(\mathrm{n}=907), 1$ $(n=2700)$, and $2(n=750)$. Patients with $\mathrm{CHA}_{2} \mathrm{DS}_{2}-\mathrm{VAK}$ score of 2 had a more than 3-fold higher risk of thromboembolism than those with a score of 0 , even though their $\mathrm{CHA}_{2} \mathrm{DS}_{2}-\mathrm{VASc}$ scores were the same.

Japanese and Chinese investigators reported that female sex may not be a risk of TE at all, at least in Japanese AF patients. ${ }^{8,17,18}$ In our study, we demonstrated that women did not have an increased risk of TE compared with men. According to Western population studies, numerous possible mechanisms explaining the difference between the sexes have been proposed, such as differences in the structure and function of the left atrium, ${ }^{19}$ endothelial dysfunction, markers of platelet activation ${ }^{20}$ and effect of hormone replacement therapy. ${ }^{21}$ However, there could also be a genetic difference among races affecting these factors, and further research is needed to verify and establish the reasons for these ethnic differences.

CKD is a well-known risk factor associated with increased risk of stroke, systemic TE and bleeding among patients with AF, $3,22,23$ This has been a consistent finding in Eastern population cohort studies., ${ }^{4,24}$ There have been numerous attempts to incorporate kidney disease into the risk stratification system, and this issue is still controversial. ${ }^{25,26}$ Previous studies have shown that anticoagulation was useful for AF patients with CKD, and CKD patients on anticoagulation showed the same risk as non-CKD patients in our cohort.

The current TE risk stratification systems such as $\mathrm{CHA}_{2} \mathrm{DS}_{2}-\mathrm{VASc}$ or $\mathrm{CHADS}_{2}$ have a lot to be improved and refined. First of all, the ethnic difference has to be considered in AF management guidelines for stroke prevention. Ethnic differences in stroke incidence, severity or mortality are generally known. ${ }^{27,28}$ Each risk factor candidate currently attracting the attention of researchers should be carefully examined from an ethnic perspective. Second, to improve the current modest predictive power for TE events, each clinical factor (hypertension, diabetes, $\mathrm{HF}$ or vascular disease, etc.) might be refined in detail. For example, duration of diabetes is independently associated with ischemic stroke risk, adjusting for risk factors. ${ }^{29}$ Among hypertensive patients, left ventricular hypertrophy is an important risk factor for stroke. ${ }^{30}$ In another study, $\mathrm{HF}$ with preserved left ventricular function was suggested to be a significant determinant of stroke in $\mathrm{AF},{ }^{31}$ based on which there was no difference in TE events between HF with and without left ventricular dysfunction. ${ }^{32}$ The prognostic importance of AF patients with HF has been previously analyzed in various settings, including clinical trials, ${ }^{33}$ outpatient cohorts, ${ }^{34}$ and within epidemiologic studies. ${ }^{35}$ Those studies mainly evaluated the risks related to $\mathrm{AF}$ in patients with reduced left ventricular systolic function. However, there is evidence regarding an association between HF with preserved ejection fraction and stroke in patients with AF. ${ }^{36}$

Recently, there has been increased interest in biomarkers to help refine the risk assessment in AF populations. ${ }^{13} \mathrm{We}$ also believe that the future of TE prediction lies in the combination of clinical factors, biomarkers, genetic factors and imaging modalities. However, we think that personalized AF treatment essentially based on clinical risk factors is important.$^{37}$ Consequently, based on our study results, the novel $\mathrm{CHA}_{2} \mathrm{DS}_{2}-\mathrm{VAK}$ scheme could be a better prognostic model for predicting TE events in Asian AF patients, using clinical factors.

\section{Study Limitations}

Several should be considered in the interpretation of these real-world, retrospective single-center cohort results. There were inherent limitations in diagnostic accuracy and event ascertainment, particularly when a patient moved away or had an outcome event in another area. Another limitation was the diagnosis of clinical factors, which was largely dependent on responsible physicians' records, leading to under- or overdiagnosis. Third, several risk factors need further validation in future studies. For example, there is a lack of evidence for assigning 2 and 1 points each for age above 75 and 65 years, respectively. Lastly, considering the ethnic aspect of this study, the results might not be immediately applicable to the Western AF population, but we hope that it will help improve the current AF guidelines in the near future by embracing ethnic variability.

\section{Acknowledgment}

Our study protocol was approved by the institutional review board of Seoul National University Hospital, and was in accordance with the Declaration of Helsinki. Informed consent was waived because of the study being a retrospective review, and it was impractical to obtain consent from such a large number of patients. The data were analyzed anonymously.

\section{Disclosures}

None.

\section{References}

1. Stroke Risk in Atrial Fibrillation Working. Comparison of 12 risk stratification schemes to predict stroke in patients with nonvalvular atrial fibrillation. Stroke 2008; 39: 1901-1910.

2. Van Staa TP, Setakis E, Di Tanna GL, Lane DA, Lip GY. A comparison of risk stratification schemes for stroke in 79,884 atrial fibrillation patients in general practice. J Thromb Haemost 2011; 9: 39-48.

3. Olesen JB, Lip GY, Kamper AL, Hommel K, Kober L, Lane $\mathrm{DA}$, et al. Stroke and bleeding in atrial fibrillation with chronic kidney disease. $N$ Engl J Med 2012; 367: 625-635.

4. Cha MJ, Oh GC, Hahn S, Choi EK, Oh S. Thromboembolic risk evaluation in patients with atrial fibrillation using a modified CHADS(2) scoring system. J Cardiovasc Electrophysiol 2012; 23: $155-162$.

5. Piccini JP, Stevens SR, Chang Y, Singer DE, Lokhnygina Y, Go AS, et al. Renal dysfunction as a predictor of stroke and 
systemic embolism in patients with nonvalvular atrial fibrillation: Validation of the R(2)CHADS(2) index in the ROCKET AF (Rivaroxaban Once-daily, oral, direct factor Xa inhibition Compared with vitamin $\mathrm{K}$ antagonism for prevention of stroke and Embolism Trial in Atrial Fibrillation) and ATRIA (AnTicoagulation and Risk factors In Atrial fibrillation) study cohorts. Circulation 2013; 127: 224-232.

6. Risk factors for stroke and efficacy of antithrombotic therapy in atrial fibrillation: Analysis of pooled data from five randomized controlled trials. Arch Intern Med 1994; 154: 1449-1457.

7. Lip GY, Nieuwlaat R, Pisters R, Lane DA, Crijns HJ. Refining clinical risk stratification for predicting stroke and thromboembolism in atrial fibrillation using a novel risk factor-based approach: The euro heart survey on atrial fibrillation. Chest 2010; 137: $263-272$.

8. Inoue $\mathrm{H}$, Atarashi $\mathrm{H}$, Okumura $\mathrm{K}$, Yamashita $\mathrm{T}$, Origasa $\mathrm{H}$, Kumagai N, et al. Impact of gender on the prognosis of patients with nonvalvular atrial fibrillation. Am J Cardiol 2014; 113: 957-962.

9. European Heart Rhythm Association; European Association for Cardio-Thoracic Surgery, Camm AJ, Kirchhof P, Lip GY, Schotten U, Savelieva I, Ernst S, et al. Guidelines for the management of atrial fibrillation: The Task Force for the Management of Atrial Fibrillation of the European Society of Cardiology (ESC). Eur Heart J 2010; 31: 2369-2429.

10. Andrassy KM. Comments on 'KDIGO 2012 Clinical Practice Guideline for the Evaluation and Management of Chronic Kidney Disease'. Kidney Int 2013; 84: 622-623.

11. Cha MJ, Oh S. Epidemiologic features of the Korean atrial fibrillation population in a single center. Arrhythmia 2014; 15: 8 .

12. Miyasaka Y, Barnes ME, Gersh BJ, Cha SS, Bailey KR, Abhayaratna WP, et al. Secular trends in incidence of atrial fibrillation in Olmsted County, Minnesota, 1980 to 2000, and implications on the projections for future prevalence. Circulation 2006; 114: 119-125.

13. Hijazi Z, Oldgren J, Siegbahn A, Granger CB, Wallentin L. Biomarkers in atrial fibrillation: A clinical review. Eur Heart $J$ 2013; 34: 1475-1480.

14. Cha MJ, Park HE, Lee MH, Cho Y, Choi EK, Oh S. Prevalence of and risk factors for silent ischemic stroke in patients with atrial fibrillation as determined by brain magnetic resonance imaging. Am J Cardiol 2014; 113: 655-661.

15. Friberg L, Benson L, Rosenqvist M Lip GY. Assessment of female sex as a risk factor in atrial fibrillation in Sweden: Nationwide retrospective cohort study. BMJ 2012; 344: e3522.

16. Knecht S, Wilton SB, Haissaguerre M. The 2010 update of the ESC guidelines for the management of atrial fibrillation. Circ $J$ 2010; 74: 2534-2537.

17. Akao M, Chun YH, Wada H, Esato M, Hashimoto T, Abe M, et al. Current status of clinical background of patients with atrial fibrillation in a community-based survey: The Fushimi AF Registry. J Cardiol 2013; 61: 260-266.

18. Lin LY, Lee CH, Yu CC, Tsai CT, Lai LP, Hwang JJ, et al. Risk factors and incidence of ischemic stroke in Taiwanese with nonvalvular atrial fibrillation: A nation wide database analysis. Atherosclerosis 2011; 217: 292-295.

19. Benjamin EJ, D’Agostino RB, Belanger AJ, Wolf PA, Levy D. Left atrial size and the risk of stroke and death. The Framingham Heart Study. Circulation 1995; 92: 835-841.

20. Conway DS, Heeringa J, Van Der Kuip DA, Chin BS, Hofman A, Witteman JC, et al. Atrial fibrillation and the prothrombotic state in the elderly: The Rotterdam Study. Stroke 2003; 34: $413-417$.

21. Wassertheil-Smoller S, Hendrix SL, Limacher M, Heiss G, Kooperberg C, Baird A, et al. Effect of estrogen plus progestin on stroke in postmenopausal women: The Women's Health Initiative: A randomized trial. JAMA 2003; 289: 2673-2684.

22. Providencia R, Marijon E, Boveda S, Barra S, Narayanan K, Le Heuzey JY, et al. Meta-analysis of the influence of chronic kidney disease on the risk of thromboembolism among patients with nonvalvular atrial fibrillation. Am J Cardiol 2014; 114: 646-653.

23. Zeng WT, Sun XT, Tang K, Mei WY, Liu LJ, Xu Q, et al. Risk of thromboembolic events in atrial fibrillation with chronic kidney disease. Stroke 2015; 46: 157-163.

24. Nakagawa K, Hirai T, Takashima S, Fukuda N, Ohara K, Sasahara E, et al. Chronic kidney disease and CHADS(2) score independently predict cardiovascular events and mortality in patients with nonvalvular atrial fibrillation. Am J Cardiol 2011; 107: $912-916$.

25. Roldan V, Marin F, Manzano-Fernandez S, Fernandez H,
Gallego P, Valdes M, et al. Does chronic kidney disease improve the predictive value of the CHADS2 and CHA2DS2-VASc stroke stratification risk scores for atrial fibrillation? Thromb Haemost 2013; 109: 956-960.

26. Kornej J, Hindricks G, Kosiuk J, Arya A, Sommer P, Husser D, et al. Renal dysfunction, stroke risk scores (CHADS2, CHA2DS2-VASc, and R2CHADS2), and the risk of thromboembolic events after catheter ablation of atrial fibrillation: The Leipzig Heart Center AF Ablation Registry. Circ Arrhythm Electrophysiol 2013; 6: 868-874.

27. Fullerton HJ, Wu YW, Zhao S, Johnston SC. Risk of stroke in children: Ethnic and gender disparities. Neurology 2003; 61: 189-194.

28. Wang Y, Rudd AG, Wolfe CD. Age and ethnic disparities in incidence of stroke over time: The South London Stroke Register. Stroke 2013; 44: 3298-3304

29. Banerjee C, Moon YP, Paik MC, Rundek T, Mora-McLaughlin C, Vieira JR, et al. Duration of diabetes and risk of ischemic stroke: The Northern Manhattan Study. Stroke 2012; 43: $1212-$ 1217.

30. Wang S, Xue H, Zou Y, Sun K, Fu C, Wang H, et al. Left ventricular hypertrophy, abnormal ventricular geometry and relative wall thickness are associated with increased risk of stroke in hypertensive patients among the Han Chinese. Hypertens Res 2014; 37: 870-874.

31. Lee SH, Choi S, Chung WJ, Byun YS, Ryu SK, Pyun WB, et al. Tissue Doppler index, E/E', and ischemic stroke in patients with atrial fibrillation and preserved left ventricular ejection fraction. J Neurol Sci 2008; 271: 148-152.

32. Banerjee A, Taillandier S, Olesen JB, Lane DA, Lallemand B, Lip GY, et al. Ejection fraction and outcomes in patients with atrial fibrillation and heart failure: The Loire Valley Atrial Fibrillation Project. Eur J Heart Fail 2012; 14: 295-301.

33. Carson PE, Johnson GR, Dunkman WB, Fletcher RD, Farrell $\mathrm{L}, \mathrm{Cohn}$ JN. The influence of atrial fibrillation on prognosis in mild to moderate heart failure: The V-HeFT Studies. The V-HeFT VA Cooperative Studies Group. Circulation 1993; 87: VI102-VI110.

34. Middlekauff HR, Stevenson WG, Stevenson LW. Prognostic significance of atrial fibrillation in advanced heart failure: A study of 390 patients. Circulation 1991; 84: 40-48.

35. Wang TJ, Larson MG, Levy D, Vasan RS, Leip EP, Wolf PA, et al. Temporal relations of atrial fibrillation and congestive heart failure and their joint influence on mortality: The Framingham Heart Study. Circulation 2003; 107: 2920-2925.

36. Olsson LG, Swedberg K, Ducharme A, Granger CB, Michelson $\mathrm{EL}$, McMurray JJ, et al. Atrial fibrillation and risk of clinical events in chronic heart failure with and without left ventricular systolic dysfunction: Results from the Candesartan in Heart failure-Assessment of Reduction in Mortality and morbidity (CHARM) program. J Am Coll Cardiol 2006; 47: 1997-2004.

37. Kirchhof P, Breithardt G, Aliot E, Al Khatib S, Apostolakis S, Auricchio A, et al. Personalized management of atrial fibrillation: Proceedings from the 4th Atrial Fibrillation competence NETwork/European Heart Rhythm Association consensus conference. Europace 2013; 15: 1540-1556.

\section{Supplementary Files}

\section{Supplementary File 1}

Figure S1. Hazard ratio for thromboembolic risk according to age group.

Figure S2. Kaplan-Meier curves for thromboembolic events according to sex and $\mathrm{CHA}_{2} \mathrm{DS}_{2}-\mathrm{VASc}$ score (oral anticoagulantnaïve patients).

Figure S3. The subgroup analysis of the female factor.

Table S1. Baseline characteristics of anticoagulant-naïve patients

Table S2. Univariate and multivariate analyses for risk factor verification (anticoagulant-naïve patients)

Table S3. Annual thromboembolic event rates (\%/year) for $\mathrm{CHA}_{2} \mathrm{DS}_{2}$-VAK and $\mathrm{CHA}_{2} \mathrm{DS}_{2}-\mathrm{VASc}$ systems (anticoagulantnaïve patients)

Table S4. Numbers of patient with changed points in $\mathrm{CHA}_{2} \mathrm{DS}_{2}-$ VAK score

Please find supplementary file(s);

http://dx.doi.org/10.1253/circj.CJ-18-0218 